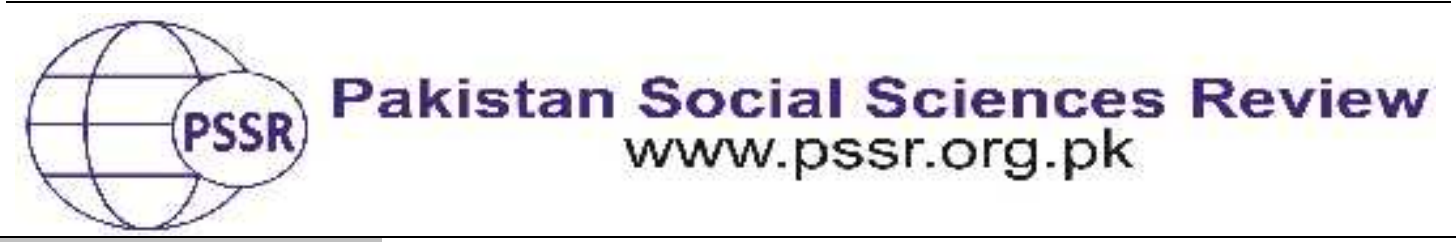

RESEARCH PAPER

\title{
Incontrovertible Nexus between Transparency and Right of Information in Pakistan's Perspective
}

\author{
Khushbakht Qaiser ${ }^{1}$ Zarfishan Qaiser ${ }^{2}$
}

1. Assistant Professor, School of Law and Policy, University of Management and Technology Lahore, Punjab, Pakistan

2. Assistant Professor. University Law College, University of the Punjab, Lahore, Punjab, Pakistan

\begin{tabular}{|c|c|}
\hline PAPER INFO & ABSTRACT \\
\hline $\begin{array}{l}\text { Received: } \\
\text { October } 21,2020 \\
\text { Accepted: } \\
\text { December } 05,2020 \\
\text { Online: } \\
\text { December } 31,2020\end{array}$ & $\begin{array}{l}\text { This paper attempts to establish an incontrovertible nexus of } \\
\text { transparency and good governance with enforcement of right of } \\
\text { information. The object of the study is to elucidate the theoretical, } \\
\text { methodological understanding of this connection and to } \\
\text { recommend how effective mechanism can be evolved by }\end{array}$ \\
\hline $\begin{array}{l}\text { Keywords: } \\
\text { Accountability, } \\
\text { Democracy, } \\
\text { Information }\end{array}$ & $\begin{array}{l}\text { engaging all the organs of the state to ensure the proper } \\
\text { implementation of the laws on this right. The study also explores } \\
\text { how a liberal information sharing regime guaranteed by law is } \\
\text { indispensable for rule of law and for sustainable development in }\end{array}$ \\
\hline $\begin{array}{l}\text { Sharing Regime, } \\
\text { Right of } \\
\text { Information, } \\
\text { Transparency }\end{array}$ & $\begin{array}{l}\text { a country. This study also explores the institutionalized } \\
\text { impediments and restraints in the opulent enforcement of this } \\
\text { right and suggests ways to deal with it by assigning various roles } \\
\text { of the legislature, executive and judiciary in implementation of }\end{array}$ \\
\hline $\begin{array}{l}\text { Corresponding } \\
\text { Author } \\
\text { zqaiser.law@pu.edu.pk }\end{array}$ & $\begin{array}{l}\text { this right. This research is based on qualitative research } \\
\text { methodology involving analytical, empirical and descriptive } \\
\text { content analysis. }\end{array}$ \\
\hline
\end{tabular}

\section{Introduction}

The right of information is indisputably entrenched upon the notion of supremacy of law and to ensure that participatory democracy is the spirit of good governance and transparency. In a democratic state free flow of information is vital instrument for instilling confidence and trust and bridging the gap between citizen and State. It makes administration more proficient and valuable in delivering services to people (Richardson, 2004). Right of Information is enshrined in the Article 19 A of the Constitution of Pakistan .This right is based on a notion that citizens are the stakeholders of all the state policies and directives; therefore, they must always be taken on board on the working of the Government; subject to some limitations and conditions . 
In a welfare state good governance is the linchpin in the whole machinery of the state craft wherein the public functionaries perform their duties with a deeper sense of commitment and in the spirit of accountability to uphold the rule of law and by enforcing the rights of the citizen. It needs, not their simple acquiescence, but their active participation. With the advent of the modern welfare State, the function of the State has multiplied. It has multiple dimensions, visible as well as invisible, 'state centric' as well as 'citizen centric' centralized as well as decentralized (David, 2006). World Bank defines governance as the way power is exercised in the management of a country's economic and social resources. Whereas good governance anticipates a progressive society, opulent involvement of public in public policymaking, the supremacy of the rule of law and free judiciary who acts as the custodian of the rights of its citizens (Amnesty International, 2011). Right of Information has recently been recognized as a gadget to ensure transparency and to curtail the peril of corruption. as has been remarked that In a Government of responsibility where the state functionaries owe responsibility to the public for their demeanor in discharge of public duties and functions, citizen have right to be acquainted with the particulars of acts done by the people who were elected by them and who perform public duties as representative of the people In Welfare State like Pakistan onerous responsibility lies on the Government to ensure the enforcement of fundamental rights envisaged in the Constitution(Ashraf, 2008).As has been aptly stated that a progressive state aspires transparency and good governance as its goal in administration of justice (Thompson, 2015).It is a well-established principle that right to information is a weapon against corruption, nepotism, and arbitrary decisions. It gives an opportunity to the citizen to have access to any public document or public action and to judge if it is transparent in accordance with law or not. Any citizen without an obligation of explaining his interest could seek information regarding any public matter or document from any public body and functionaries.

Access to information and freedom of information are articulated in alternative to each other and give the identical legal foundation which implies a fundamental right of an individual to demand discovery of any information kept by public authorities subject to limitations and statutory exceptions. With the passage of time the right of information has acquired the status of Jus Cogen)in the international legal system(Bishop, 2012).a norm which ought to be acknowledged and declared as a guarantee to implement other basic human rights. RTI thus shifts from a need-toknow principle to a right to know principle.

The Constitutional guarantees of the RTI have reverberations on all the organs of the state as well as on the functionaries, Legislature to enact laws for the proper implementation of this fundamental right then it makes incumbent upon the government(executive) to make policies and execute the mandate of the law and then to casts a heavy responsibility on the judiciary to police existing laws. It is suggested that these enactments on RTI have a twofold purpose, firstly they ingenerate access by evolving mechanisms and procedures for request procedures, 
deadlines appeals and other ancillary matters and then imposes liabilities for nonconformity of the provisions thereof (Mukhtar, (2006) .

\section{The Legal Framework for Right of Information in Pakistan}

The Constitution provides that every Citizen shall have the right to have access to information in all matters of public importance subject to regulation and reasonable restrictions imposed by the law (Article $19 \mathrm{~A}$ ). In order to implement the spirit of the right of the information in the Constitution, following enactments have been made.

- Right of Access to Information Act, 2017,

- Punjab Transparency and Right to Information Act 2013,

- KPK Right to Information Act, 2013,

- Sindh Transparency and Right to Information Act, 2016

- Balochistan Freedom of Information Act, 2005.

The RTI law (Right of Access to Information Act 2017) has a broad scope of application, extending to the executive, legislative branch and organizations that undertake public functions. The very object of the Access to information Act 2017, as envisaged in its preamble is to promote good governance and rule of law by effectuating and infusing the true spirits of transparency and accountability in government's infrastructure and that is possible only by providing free access to records held by the public authorities effecting lives of the public. Since it has become a universally accepted phenomenon that sustainable development and economic growth is aligned with transparency and supremacy of law and that can be achieved only when there are optimum checks on the menace of corruption and inefficiency in Governmental department it has become indispensable to evolve mechanisms in which citizens can have access to information and records related to their life (Ashraf, 2006). Another reason for emphasizing on the need to enforce RTI is that continuous monitoring of the performance of the public authority's scrutiny of the records and access to information to all it will prove to be a most effective parameter to ascertain transparency and accountability It is stated that objectivity, openness, and accountability are the basic virtues which a government must ensure to implement the system of accountability for public functionaries to work.

From perusal of the Act, it is evident that Right of information in the Act includes information kept by the government and statutory bodies. Section 3 of the Act lays down a mandatory provision which provides that subject to reasonable and statutory exemptions no person shall be denied of his right to acquire information (Ali, 2006). Section 6 of Act enlists certain documents to be declared as public documents, and accessible to public i.e., policy statements, detail of expenditures incurred by any public body in discharge of public duties, audit reports, evaluation reports, investigation reports. Whereas Section 7 of the Act exempt certain public documents from the application of Section 6 thereby not accessible for public i.e., 
minutes of meetings, notes made on official files, record relating to defense forces, financial institutions, private and confidential records of private individuals held by public functionaries. Section 8 of Act directs the concerned authorities to make all the authorized records accessible by the public by computerization voluntarily.

Section 9 provides for the appointment of a designated officer whose duties and function are to ensure that requests of the applicant are duly and promptly complied with and all the public bodies are performing their duties pertaining to such request in accordance with this Act and law. Section 13 of the Act stated that such designated officer will provide a written acknowledgement in relation to the request so received. Section 11 of the Act provides the modus operandi for a citizen to apply for the information through a designated official from the concerned department. Section 14 of the Act provides a time of 10 days within which the request for information is to be responded, however, this period may be extended further. Section 16 of the Act exempts certain documents/ records from being disclosed if such disclosure is averse to the interest, sovereignty, and integrity of the State and prejudicial to the safety, life, health, and interest of any individual, body politic or community. Section 17 gives a right of appeal to the applicant who finds himself aggrieved by the decision of the designated officer to the Information Commission. Section 20 of the Act gives power to the Information Commissioner to order any public body to disclose information, or to impose fine who violated the provisions of the Act willfully without any lawful justification. Moreover, the Information commission is empowered to make rules consistent with the mandate given by the Act.

Section 22 of the Act deals with important aspect of this Act which incurs criminal liability on any person who willfully obstruct or violate the provisions of this Act or who creates hurdles in exercise of this right to acquire information, be punished with imprisonment which may extend to two years and shall also be liable to pay fine not less than rupees of one hundred thousand.

\section{Right of Information and its Nexus with Good Governance and Transparency}

Another important facet of the RTI is that it makes democracy functional in the real sense. It does not only create social awareness among the public but also has many socio-economic benefits one of which is the confidence of the public on Government in the implementation of their rights but also breaks the myth of official secrecy (Shepherd, (2015). The edifice of good governance in twenty-first century is based upon certain essential feature those are the doctrine of collective responsibility, participatory development, access of information, increased vigilance, transparency, accountability, and responsiveness (Toby, 1999). When RTI is harnessed as a tool it becomes an obligatory tangible quality for the citizens and the administrators (Foldes, 2016). This makes citizens empowered to exercise their political, social, and economic rights in a more meticulous manner, the Government too can take well informed upright decisions with the presumption that they shall be answerable for their actions. 
Right of information has a direct liaison with the doctrine of accountability transparency which in practice achieves good governance. As has been rightly remarked that every growing society aspires the ideal of good governance as a parameter to measure its efficiency in administration (Jain, 2014). In addition to this a progressive democratic society is based on informed citizenry believing that citizens are the direct stakeholders and must be acquainted with all the acts which affect their lives either directly or indirectly. Thus, there is a straight and indisputable connection between the RTI, transparency and good governance (Ackerman\& E (2006). A translucent system of governance undertakes a transparent and responsible state by upholding all the virtues a democratic state aspires to achieve. As has been stated that access to official information held by public authorities is the touchstone of a proficient and vibrant representative democracy (Aceves, 2000). For ideal of democracy to flourish and transparency to be effectuated maximum disclosure of information must be ensured because upon this foundation only a democratic society prosper and develop. It is also believed that nothing supplements the doctrine of checks and balances more opulently than RTI as it infuses transparency in the very system of governance and promotes the culture of openness and accountability.

RTI gives an insight to the citizens to know about the facts and dealings undertaken by the Government and inculcate the spirit of participatory democracy in the very system of the state subject to law (Sharan, 2011). No governmental set-up can operate in a way to offer absolute access to all proceedings and documents. As rightly remarked that complete transparency not only would create prohibitive logistical problems and expenditures, but it would hinder most vital operations and violate the interests of the individuals who give personal information to the government (Jain, 2012), therefore, RTI is not an absolute right, it is subject to reasonable restrictions and exemptions imposed by law and Constitution. The justification for these limitations and restrictions includes the interests of the State. Safety security and life of citizens of the state and public order.

In State of Uttar Pradesh v. Raj Narain, it was held that the people of this country have a right to know every public act, everything that is done in a public by their public functionaries (Anand, 2011). They are enticed to know the particulars of every public transaction in all its bearing The right to know, which is derived from the concept of freedom of speech, though not absolute, is a factor, which should make one wary, when secrecy is claimed for transactions, which can, at any rate have no repercussion (Fox, 2007).Transparency has become the norm of day. The degree of transparency in each society measures the maturity of that society (Bishop, 2011). It is necessary for any democratic society to win the confidence and credibility of the people it governs because this will ultimately lead to sustainable development and economic growth. However, at times, transparency and confidentiality must be reconciled for the greatest good of the greatest number. Nevertheless, good governance pre-supposes transparency to promote accountability in administration, though confidentiality may be permissible in matters that have strategic importance, 


\section{Conclusion}

In modern democracies and specially after the emergence of the concept of welfare state the functions of the state has multiplied and has become more complex and complicated and this gives way to a lot of classified and unrevealed ways of handling policy and administrative matters by the state functionaries giving absolute autonomy to the departments to manage accordingly. RTI all over the world is considered as an efficient and systematic check on the functioning of these statutory bodies and departments who perform public duties and deal with matters of public importance(Mendel, T. (2003). RTI helps the citizen to know about the affairs of the Government who in every democratic society are answerable to people they govern. Because if there are no checks and people do not have access to information then every object of the welfare state shall be defeated. Dearth of transparency and lack of mechanisms furthering accountability are the main reasons of corruption in a state. Access to public records provides people the chance to take part in civic life to assist to lay down priorities, and to grasp governments answerable and accountable. A free flow of information is a vital instrument for constructing confidence and trust between a management and populace. It makes administration more proficient and valuable in delivering services to people. It was stated in the survey conducted by CPDI in September 2019 that the federal as well as provincial governments has received hundreds of information requests but in most of the cases, the government institutions chose not to respond.

From the perusal of various enactments on RTI it is evident that these laws provide a practical regime for this right to flourish and transparency to be executed in accordance with the spirit of law (Tiwari, 2012). Rules must be made to ensure that the procedures are easy economical less time consuming not complicated and devoid of any red-tapism. It must ensure continuous monitoring, training, and evaluation of departments by independent and impartial body. Overall status of RTI in Pakistan is not pleasing. Result oriented efforts must be made both by the citizens, as well as governments by educating people and creating awareness amongst the public functionaries that it will be for their own good if they will let their official acts pass the litmus test of scrutiny through systematic checks and balance.

This right has become an indispensable reality as has been stated that in modern democracies citizens have the right to know about the affairs of the Government, which has been elected by them and about the policies aimed at their welfare formulated by the government (Saluke 2008). This is undoubtedly an established norm that (RTI) is a condition precedent for transparency rule of law and good governance and in fact gives a platform for the realization of all other human rights including education and health care that have intense and pervasive impact on all the human activities. The reason behind this presumption is that rule of law nurtures only in those societies which are open transparent and ensure due process of law. Wherein all the state functionaries perform their functions and discharge their duties in accordance with law and work on the principle of checks and balance so that powers can be exercised within the prescribed limits. 


\section{Recommendations}

All the above mentioned RTI laws are enacted to protect Constitutional right of information and to have access to public record subject to limitations imposed by law, however, mere enactment is not enough, it needs effective mechanisms to enforce the mandate envisaged in these laws, the aspirations it aims to achieve and the standard it upholds. This is possible only by a political will determination and effective response by all the stakeholders i.e. public, and public functionaries and to by providing a plausible paradigm for its practical execution, however, the culture of secrecy has proved to be the biggest impediment in the true implementation of right of information(Richardson, (2004). Despite of the undertakings made in all the enactments and objects laid down therein this right lacks proper implementation, and this is due to dearth of political will and lack of awareness about the significance of transparency and openness (Ashraf, 2008). It has been stated that, the most important requirement is to make a paradigm shift from mores of secrecy to that of openness, but the critical role vests on political and governmental ownership (Riegner, 2017).

There is a dire need to infuse this spirit in very system that right of information is not merely a right but also a responsibility of everyone to keep a check on the functioning of the institutions to make sure that government is performing its functions and performing its duties in accordance with law, in translucent manner. The rules must be made to make sure that any kind of murkiness in the broadcasting of information otherwise than in due course of law is not acceptable and should be done away with. The latest law on RTI undertakes to make RTI more functional, growing, practical, possible, and significant, as it inspires the citizen to earnestly contribute to the ideal of good governance (Mukhtar, 2006) The State functionaries must aid in the enforcement of this right by evolving the guiding principle of maximum disclosure and minimum exemptions from disclosure. It is also very important to take certain concerns in mind when we intend to talk about the implementation of complete enforcement of RTI. These include greater awareness, availability of opulent resources and ownership of the right across the board especially at the political and governmental level. There are issues related to lack of financial resources, poor infrastructure, lack of political will, dearth of uniform policies, and lack of skill pertaining to information management regime.

However, with political will and resolve improvements can be made and paradigm shift can be introduced from the culture of secrecy to prudence of openness, more proficient and practical rules and policies must be made regarding the procedure to be followed by the officers dealing with the requests for information and matter incidental and ancillary to it. It is also suggested that harm test must be introduced for all the exceptions and exemptions provided in the law. The RTI Act provides a long list of types of records and documents that should be proactively published but it does not mention that which information must be available online so this must also be considered, and a viable check must be made to 
see if the directions are complied with by the government functionaries or not. Moreover, it must be made incumbent upon authority to publish an annual report containing requisite information on its functions, activities, expenditure, regulations notifications directives policy related matters and decisions etc. The role of the state does not end with the mere enactment of the laws by its legislative organ or formulation of rules and policies by its executive organ, but it must always exercise supervisory control to ensure their proper implementation.

From the perusal of all these enactments, regulations and policies made for the implementation of these laws it is evident that this right could have been opulently forced, however, it has never so owned to the culture of secrecy prevailing therein, and therefore, the question is not of possibility of enforcement but of probability of enforcement. There is less likelihood or probability of enforcement of this right in Pakistan because the culture of transparency is absent from governmental set up. Despite of the fact that peoples are exercising RTI in Pakistan yet the government's response to these information requests is not very effective. According to a survey conducted by (CPDI in2019) Out of 2,635 information requests filed during last five years, the government responded only to 788 almost 29 percent (Centre for Peace and Development, 2019). As has been rightly remarked that, the culture of official secrecy has been one of the strongest living aspects of our colonial legacy (Foldes, 2016). Information about high profile cases were not made public by the Government and this culture permeates in all government offices in Pakistan, the government must take it on itself as duty to supply the requested information to that citizen, unless defined exemptions apply; and must endorse the principle of maximum disclosure of information, subject only to limited exemptions. 


\section{References}

Anand, P. B. (2011). Right to information and local governance: An exploration. Journal of Human Development and Capabilities, Vol.12 Issue 1, 135-151

Ashraf, T. (2008). Empowering people through information: A case study of India's Right to Information Act. The International Information \& Library Review, Vol.40 Issue. 3,148-152.

Ackerman, J. M., \& Sandoval-Ballesteros, I. E. (2006). The global explosion of freedom of information laws. Admin. L. Rev., Vol.58, 85.

Aceves, W. J. (2000). The Right of Information on Consular Assistance in the Framework of the Guarantees of the Due Process of Law. Advisory Opinion OC16-99. American Journal of International Law, 555-563.

Bishop, A. (2012).Access to Information as A Human Right Lfb Scholarly Publishing,Journal of Information Policy, Vol. 2 204-206

David ,B (2006). Freedom of Information Around the World :A Global Survey of Access to Government Information Laws Vol 3168 Pages

Fox, J. (2007). The uncertain relationship between transparency and accountability. Development in practice, Vol.17 Issue (4-5), 663-671.

Foldes, A. (2016). Migration of Civilian and National Security Access to Information Norms. J. Int'l Media \& Ent. L., Vol.7, 14

Jain, A. (2012). Good Governance and Right to Information: A Perspective, Journal of The Indian Law Institute, Vol. 54, 506-519

Tiwari, K (2012). Corruption, democracy, and bureaucracy. Theoretical and Applied Economics, Vol.9 Issue. 9, 17.

Mukhtar,A. (2006). Lack of transparency and freedom of information in Pakistan: A report on the analysis of government policy and practices, and realistic options for reform. Policy Documentation Centre, Pakistan

Mendel, T. (2003). Freedom of information as an internationally protected human right. Comparative Media Law Journal, Vol.1 Issue.1, 39-70.

Patrik, Bi.(2006)Freedom of information and openness: Fundamental Human Rights? Administrative Law Review vol 58,No 1 issue( 1-2) 177-218

Riegner, M. (2017). Access to information as a human right and constitutional guarantee. A comparative perspective. Verfassung und Recht in Übersee/Law and Politics in Africa, Asia and Latin America, Vol.50 Issue.4, 332-366. 
Richardson, B. (2004). The Public's Right to Know: A Dangerous Notion, Journal of Mass Media Ethics.MIS Quaterly 34(4):989-1015

Shepherd, E. (2015). Freedom of information, right to access information, open data: who is at the table? The Round Table, Vol.104 Issue. 6, 715-726.

Sharan, S. (2011). Reviewing the Right to Information through the prism of Indian policy process. Focus, Vol. 14, Issue 4-1.

Saluke, A. (2008). Ad-blocking software as third-party tortious interference with advertising contracts. Bus. L. Rev., Vol. 7, 87.

Thompson, D. F. (2015). John Stuart Mill and representative government. Princeton University Press.) 